\title{
Paternal smoking and maternal protective behaviors at home on infant's saliva cotinine levels
}

\author{
Man-ping Wang ${ }^{1}$, Yi-nam Suen ${ }^{2}$, Bonny Yee-man Wong ${ }^{3}$, William Ho-cheung Li ${ }^{1}$, David Soo-quee Koh ${ }^{4,5}$, Tai-hing Lam ${ }^{6}$ and
} Sophia Siu-chee Chan ${ }^{1}$

BACKGROUND: We investigated the association between paternal smoking, avoidance behaviors and maternal protective actions and smoke-free home rules with infant's saliva cotinine in Hong Kong.

METHODS: Six hundred and seventy-five non-smoking mothers (mean age 32.6 years) who attended the maternalchild health clinics with their newborns aged $\leq 18$ months completed a questionnaire about paternal smoking and avoidance behaviors, maternal protective actions, smoke-free rules at home, and infant's second-hand smoke (SHS) exposure. Three hundred and eighty-nine infants provided saliva sample and its cotinine was tested.

RESULTS: The geometric mean of infant's saliva cotinine was $1.07 \mathrm{ng} / \mathrm{ml}$ (95\% confidence interval (Cl): 0.98, 1.16). Infants living in smoking families with SHS exposure had significantly higher cotinine level than in non-smoking families (adjusted $\beta=0.25,95 \% \mathrm{Cl}: 0.16,0.33)$. Paternal smoking near infants (within $1.5 \mathrm{~m}$ ) was associated with higher cotinine level (adjusted $\beta=0.60,95 \% \mathrm{Cl}: 0.22,0.98)$, which was not reduced by avoidance behaviors (e.g., smoking in kitchen or balcony). Even fathers smoking $\geq 3 \mathrm{~m}$ away from infants was associated with higher cotinine level than non-smoking families (adjusted $\beta=0.09,95 \% \mathrm{Cl}: 0.01,0.16)$. Maternal protective actions and smoke-free home rules were not significantly associated with reduced cotinine level.

CONCLUSION: Paternal smoking avoidance, maternal protective actions, and smoke-free policy at home did not reduce infant's saliva cotinine.

$\mathbf{S}$ econd-hand smoke (SHS) in children causes adverse health effects and increases medical costs and the likelihood of smoking initiation $(1,2)$. Home is the major source of SHS exposure in children. Some smokers are aware of the harms of SHS and make efforts to avoid exposing children to SHS (3). SHS exposure in young children is best measured through the biomarker saliva cotinine as it is noninvasive and easy to conduct (4). Total smoking ban at home (smoke-free home) predicted more smoking reduction and cessation and was associated with lower cotinine level in children than any partial smoking ban, which is defined as allowing smoking at home at specific places or times (5-7). However, adoption of smoke-free home rules is still uncommon. For instance, only less than half $(\sim 40 \%)$ of the families in the United State and United Kingdom adopts smoke-free home rules $(8,9)$. One previous study has found that interventions to protect children from SHS at home through encouraging parents to reduce smoking or quit had nonsignificant effects on reducing the cotinine level (10). More in-depth understanding of parent's smoking behaviors at home and the protective strategies for SHS exposure may inform and provide information to design more effective interventions.

Predictors of SHS exposure in children at home have been widely studied, but little is known about the details of parental smoking and avoidance behaviors at home, and non-smoking parent's protective actions on reducing SHS exposure in children (11). Previous studies have differentiated children's SHS exposure by the place where father smokes (indoors or outdoors) (12), or by the degree of smoking ban enacted at home (complete, partial, or nil) (13). These studies support the importance of complete smoking ban at home, but many people still allow smoking at home without any restrictions or just restrict smoking in specific rooms. In contrast, we cannot identify any studies investigating the association between the places where fathers smoke and infant's SHS exposure at home. A previous study has found that one-third (29.3\%) of smoking fathers smoked near the children $(<3 \mathrm{~m})$ at home in Hong Kong while non-smoking mothers attempted to reduce the harms of SHS in children by enacting protective actions such as "opening the windows," "asking the father not to smoke near the child,", "moving the child away from the smoke," and "remove the ashtray" (14). However, it remains unclear how these smoking avoidance and SHS protective behaviors at home affect children's cotinine level.

${ }^{1}$ School of Nursing, The University of Hong Kong, Hong Kong SAR, China; ${ }^{2}$ Department of Psychiatry, the University of Hong Kong, Hong Kong SAR, China; ${ }^{3}$ Department of Health and Physical Education, the Education University of Hong Kong, Hong Kong SAR, China; ${ }^{4}$ PAPRSB Institute of Health Sciences, Universiti Brunei Darussalam, Brunei Darussalam; ${ }^{5}$ Saw Swee Hock School of Public Health, National University of Singapore, Singapore, Singapore; ${ }^{6}$ School of Public Health, The University of Hong Kong, Hong Kong SAR, China. Correspondence: Tai-hing Lam (hrmrlth@hku.hk)

Received 21 August 2017; accepted 3 October 2017; advance online publication 13 December 2017. doi:10.1038/pr.2017.279 
There is no safe level of SHS exposure, and most guidelines recommended a total smoking ban at home (15). Children living in multiunit housings are particularly prone to SHS exposure due to shared ventilation system and crowd living environment (16). This is particularly a concern in densely populated cities such as Hong Kong where children live in small and crowded apartments. Comprehensive smoke-free legislation that bans smoking in most public indoor places has been implemented since 2007 with an observed displacement of SHS into the home of young children and an increase in mother's SHS protective behaviors $(14,17)$. We investigated the associations between paternal smoking and avoidance behaviors, maternal SHS protective behaviors and smoke-free rules at home with infant's saliva cotinine level.

\section{METHODS}

\section{Subjects}

From April to September 2012, 771 non-smoking mothers who had new born aged $\leq 18$ months were recruited from four major Maternal and Child Health Centers in Hong Kong (response rate: $66 \%$ ). All mothers completed a self-administered questionnaire, which collected information on family smoking status, paternal smoking and avoidance behaviors, maternal protective actions, and smoke-free rules at home that aimed to protect children from SHS exposure. Current analysis only included non-smoking families or smoking families with the father as the only smoker $(n=675)$ with valid cotinine samples $(n=389)$. Family smoking status was categorized into three types: non-smoking families (no smokers in the family), smoking families without SHS exposure at home (had a smoking father who did not smoke at home), and smoking families with SHS exposure at home (had a smoking father who smoked at home). This study gained ethical approval from the Institutional Review Board of the University of Hong Kong/Hospital Authority Hong Kong West Cluster.

\section{Measurements}

Salivary cotinine was used to objectively measure infant's SHS exposure as it correlates well with parent-reported SHS exposure in young children (18) and avoids the limitation of other methods such as parental concerns about invasive procedure for serum sampling (19), limited infant hair growth for hair nicotine (20), and uncontrolled excretion of urine samples for cotinine test (21). Trained research staff used sorbettes (a wand with a small sponge on the end) to collect saliva samples from the infants and stored them in the $2 \mathrm{ml}$ tubes, which would be immediately frozen in ice-pads and transferred to laboratory freezer. The samples were sent for assay by the National University of Singapore using enzyme-linked immunosorbent assay. The lower limit of cotinine sensitivity was $0.05 \mathrm{ng} /$ $\mathrm{ml}$ (range: $0.06-200 \mathrm{ng} / \mathrm{ml}$ ) (22).

In the questionnaire, non-smoking mothers reported the places and the distance from children when the father smoked at home, their protective actions, and smoke-free home rules. The mothers reported yes or no to 8 of the places at home where the father smoked, which included (1) mother's and father's bedroom, (2) living room, (3) dining room, (4) bathroom, (5) kitchen, (6) balcony, (7) at child bedroom, and (8) rooftop. The distance from children when the father smoked at home was assessed by two dichotomous (yes/no) questions of (1) "Does father smoke $\leq 3 \mathrm{~m}$ from the child at home?" and (2) "Does father smoke $\leq 1.5 \mathrm{~m}$ from the child at home?" The answers of the two questions were then combined and summarized as " $>3 \mathrm{~m}$ ", "3-1.51 m," and " $\leq 1.5 \mathrm{~m}$."

Maternal SHS avoidance actions were measured by asking: "When smokers smoke at home, how often do you: (1) take the child away from the smoke?, (2) open the windows?, (3) post a 'No Smoking' sign at home?, (4) encourage father to reduce smoking/quit?, (5) encourage father not to smoke inside the home?, and (6) encourage father not to smoke near the child?" Smoke-free home rules were assessed by the following questions: "if mothers asked smokers to extinguish cigarettes before entering the home" and "if mothers banned any smoking inside home at the following seven places: (i) living/dining room, (ii) bathroom, (iii) kitchen, (iv) mother's bedroom, (v) child's bedroom, (vi) balcony, and (vii) within 3 meters of the child". The responses for each action/rule were "always," "usually," "rarely," and "never" and were dichotomized as always/usually vs. none/rarely. The total number was summed into 0-6 for avoidance action and 0-8 for smoke-free rules.

Other collected information included sociodemographic characteristics (infant's gender, the highest parental education, household income, and housing type) and infant's SHS exposure outside the home, which was defined as exposed to SHS at any of the following places: public areas (e.g., bus stops, streets, and parks), outside restaurants, inside the building that they lived (e.g., corridors and garbage room), someone's home, and never exposed.

\section{Statistics analysis}

Owing to the skewed distribution, the salivary cotinine data were logtransformed and geometric mean was used. Cotinine levels between sociodemographic characteristics were compared using independentsamples $t$-test or ANOVA. Generalized linear model ( $\beta$-coefficient) with the adjustment of children's age and SHS exposure outside the home, parental highest educational attainment, housing types, and household income (Model 1) was determined. To examine the effects of paternal smoking behaviors and maternal SHS protective actions at home, only households with reported paternal smoking at home $(N=90)$ were included. Children's cotinine level was compared separately between (Model 2) and mutually for (Model 3) paternal smoking behaviors (places and distance from children), maternal SHS avoidance actions, and smoke-free rules in smoking households by using generalized linear model ( $\beta$-coefficient).

\section{RESULTS}

There was little difference in the sociodemographic characteristics and smoking status between the families with and without valid infant's cotinine level (Supplementary Table S1 online). Among the 389 infants who provided valid cotinine samples, $89.7 \%$ of their parents had senior secondary or above education; $60.4 \%$ had monthly household income $\geq \mathrm{HK}$ $\$ 20,000$ (US $\$ 1=\mathrm{HK} \$ 7.8$ ); $42.5 \%$ lived in private housings; and $37.0 \%$ had a smoking father, in which $62.5 \%$ were exposed to SHS at home (Table 1).

The overall geometric mean of cotinine levels was $1.07 \mathrm{ng} /$ $\mathrm{ml}$. It was significantly higher in smoking families with SHS exposure $(1.63 \mathrm{ng} / \mathrm{ml})$ when compared with the smoking families without SHS exposure $(0.90 \mathrm{ng} / \mathrm{ml})$ and the nonsmoking families $(0.95 \mathrm{ng} / \mathrm{ml})(P<0.001)$. Fathers smoking at a distance very close to the children $(\leq 1.5 \mathrm{~m})$ was significantly associated with higher cotinine level in children when compared with smoking $1.5 \mathrm{~m}$ and $3 \mathrm{~m}$ away from the children ( 6.23 vs. 1.88 and $1.36 \mathrm{ng} / \mathrm{ml}, P=0.003)$. Infant's cotinine levels were higher if fathers smoked in self-bedroom (19.11 vs. $1.54 \mathrm{ng} / \mathrm{ml}, P=0.001)$ and living rooms (4.69 vs. $1.49 \mathrm{ng} / \mathrm{ml}, P=0.007$ ) (Figure 1). Maternal avoidance actions and places at home with smoking ban were not associated with infant's cotinine level (Figures 2 and 3).

Infants in the families with SHS exposure had significantly higher cotinine level than in non-smoking families (adjusted $\beta=0.2595 \%$ confidence interval (CI): 0.16, 0.33) (Table 2). 
Table 1. Infant's saliva cotinine levels by different characteristics $(N=379)$

\begin{tabular}{lccc}
\hline & $\mathrm{N}(\%)$ & $\begin{array}{c}\text { Cotinine level } \\
\text { Geometric mean } \\
(\mathrm{ng} / \mathrm{ml})(95 \% \mathrm{Cl})\end{array}$ & $\mathrm{P}$ value \\
\hline $\begin{array}{l}\text { Total } \\
\text { Sex }\end{array} \quad 389(100.0)$ & $1.07(0.98,1.16)$ & \\
$\quad$ Male & $204(52.4)$ & $1.02(0.91,1.14)$ & 0.25 \\
$\quad$ Female & $185(47.6)$ & $1.12(0.98,1.28)$ &
\end{tabular}

$\begin{array}{lrr}\begin{array}{l}\text { Parental highest } \\ \text { education }\end{array} & & \\ \quad \text { Junior secondary } & 40(10.3) & 0.90(0.73,1.09) \\ \begin{array}{l}\text { Senior secondary } \\ \text { Postsecondary }\end{array} & 186(47.8) & 1.15(1.00,1.33) \\ & 163(41.9) & 1.02(0.90,1.14)\end{array}$

Family income (HKD/ month, USD $1=H K D$ 7.8)

$<10,000$

$40(10.3)$

$1.13(0.76,1.69)$

$10,000-19,999$

$114(29.3)$

$1.13(0.96,1.33)$

20,000-29,999

84 (21.6)

$1.01(0.86,1.18)$

$\geq 30,000$

$151(38.8)$

$1.04(0.91,1.18)$

Housing type

Public rental housing 138 (35.5)

Subsidized sale flats $65(16.7)$

Private permanent $161(41.4)$

housing

Others

Had outdoor SHS

exposure in past 7 days

$$
\text { Yes }
$$

No

$212(54.5)$

$1.00(0.90,1.11)$

$1.15(1.00,1.33)$

$1.19(1.00,1.41)$

$0.92(0.75,1.13)$

$0.99(0.88,1.10)$

$1.40(1.03,1.92)$

Family smoking and SHS exposure at home

$\begin{array}{lrl}\begin{array}{l}\text { Non-smoking family } \\ \text { Smoking family }\end{array} & 245(63.0) & 0.95(0.87,1.04) \\ \begin{array}{l}\text { without SHS } \\ \quad \text { Smoking family with }\end{array} & 90(23.1) & 0.90(0.72,1.11) \\ \text { SHS } & & 1.63(1.30,2.04)\end{array}$

Paternal smoking distance to children at home $(m)^{\mathrm{a}}$

$\begin{array}{lcl}>3 & 62(68.9) & 1.36(1.04,1.77) \\ 3-1.51 & 22(24.4) & 1.88(1.30,2.73) \\ \leq 1.5 & 6(6.7) & 6.23(1.36,28.50)\end{array}$

$\mathrm{Cl}$, confidence interval; SHS, second-hand smoke.

${ }^{a}$ Among smoking families with SHS $(N=90)$.

The number of places where father smoked was associated with increased infant's cotinine levels in the crude model $(\beta=0.16,95 \%$ CI: $0.03,0.30)$ and the model adjusting for sociodemographic characteristics (adjusted $\beta=0.15,95 \% \mathrm{CI}$ : $0.18,0.29)$, but became nonsignificant after adjusting for other paternal smoking and maternal protective actions. Fathers smoked $\leq 1.5 \mathrm{~m}$ around the children was associated with increased infant's cotinine levels in the crude $(\beta=0.66,95 \%$ CI: $0.28,1.04$ ) and all other models adjusted for sociodemographic characteristics (adjusted $\beta=0.67,95 \% \mathrm{CI}$ : $0.30,1.04)$, plus the number of places at home where fathers smoked (adjusted $\beta=0.62,95 \%$ CI: $0.26,0.99$ ) and plus maternal protective actions (adjusted $\beta=0.60,95 \%$ CI: 0.22 to $0.98)$. Infant's cotinine level was not associated with maternal protective actions and the number of smoke-free home rules in the adjusted models.

0.75

0.053

0.10

$<0.001$

\section{DISCUSSION}

To our best knowledge, only two studies examined the factors that associated with SHS exposure of infants in the East $(23,24)$. Our results are in line with the study by Baheiraei et al. (24) that infant's SHS exposure is associated with home smoking restrictions. Also, our study is the first to comprehensively investigate the associations between paternal smoking and avoidance behaviors, regarding the places of smoking and the distance away from the infants during smoking, maternal SHS protective actions, and smoke-free home rules with infant's saliva cotinine level. In this study, more than one-fifth $(21.1 \%)$ of the infants were exposed to SHS from paternal smoking at home. It is lower than the previous local study in infants (33.4\%) (25) while we only included home exposure prevalence. Meanwhile, it is much lower than the preschoolers (63.2\%) (13), probably due to stronger maternal protection and unacceptability of exposing infants to SHS by fathers.

SHS exposure at home was significantly associated with substantial increase in saliva cotinine levels in infants $(P<0.001)$. In this study, the cotinine levels among infants who were exposed to paternal smoking at home were just slightly lower $(1.63 \mathrm{ng} / \mathrm{ml})$ than the school-aged children $(1.75 \mathrm{ng} / \mathrm{ml})$ who lived with smoking parents without home smoking restriction in the United Kingdom (26). Such intense SHS exposure is particularly detrimental to infants, suggesting that effective interventions to reduce the harms are needed. Given that there is no safe level of SHS exposure, the small effect sizes for increased cotinine in relation to the number of places father smoked $(\beta=0.13, P<0.05)$ and distance between father smoked and children $(\beta=0.48, P<0.01)$ are clinically significant. Although one previous study has reported that preschool-age girls are more exposed to SHS than boys (27), we did not find such difference in infants whose mobility is still limited in our study, no matter in smoking (mean saliva cotinine level in boys: $1.29 \mathrm{ng} / \mathrm{ml}$; in girls: $1.13 \mathrm{ng} / \mathrm{ml} ; P=0.98$ ) or non-smoking families (mean saliva cotinine level in boys: $0.87 \mathrm{ng} / \mathrm{ml}$; in girls: $1.19 \mathrm{ng} / \mathrm{ml}$; $P=0.18)$ (not shown in tables). 


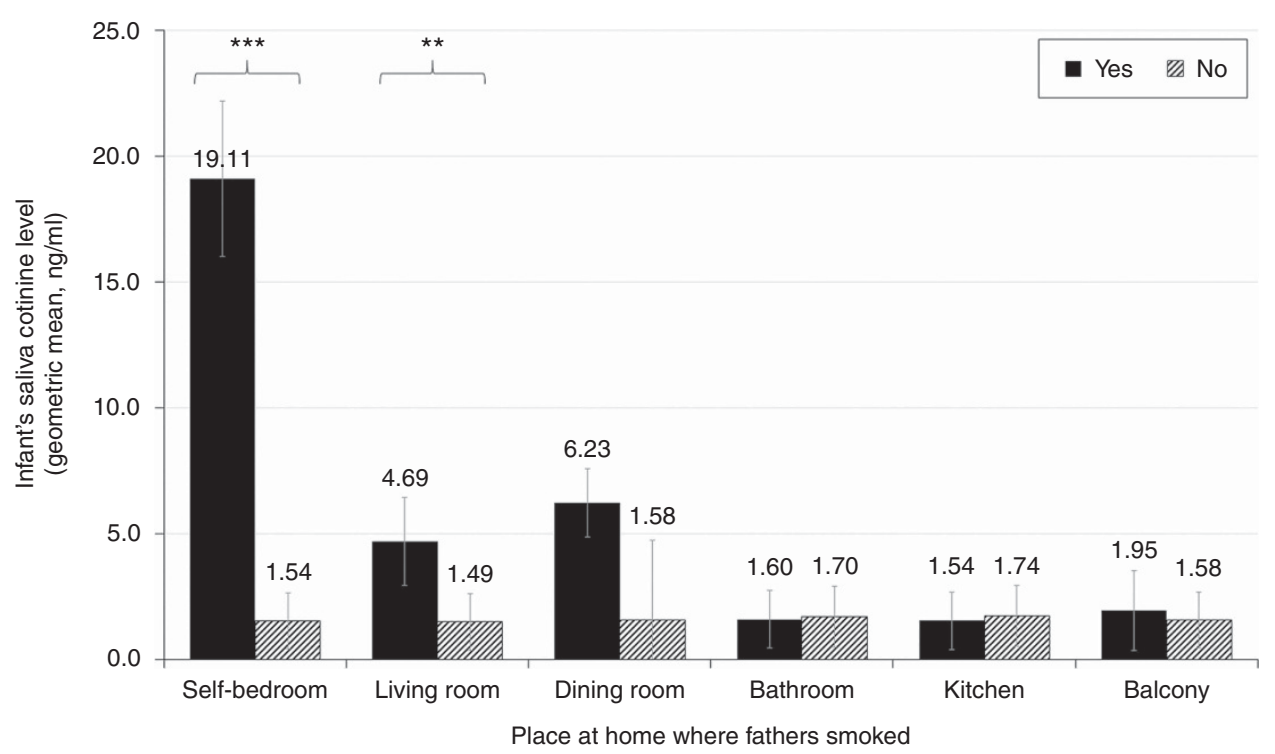

Figure 1. Places where fathers smoked at home and infant's saliva cotinine level. ${ }^{* * *} P<0.01 ;{ }^{* *} P<0.05$.

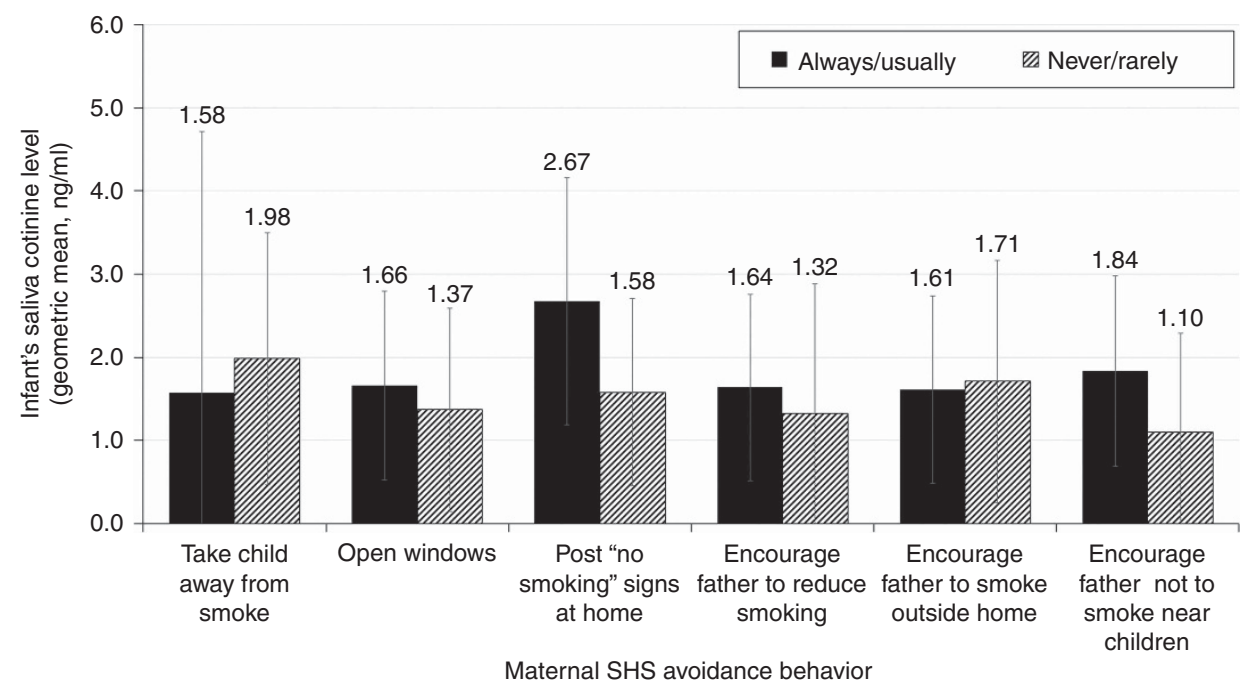

Figure 2. Maternal avoidance actions and infant's saliva cotinine level.

Similar cotinine levels were observed in infants living in non-smoking families $(0.95 \mathrm{ng} / \mathrm{ml})$ and smoking families without SHS exposure at home $(0.89 \mathrm{ng} / \mathrm{ml})$. The results suggested the protective effect of the total smoking ban on children's SHS exposure at home. Cotinine levels in infants living in non-smoking families in our studies $(0.95 \mathrm{ng} / \mathrm{ml})$ were higher than living with non-smoking parents $(0.14 \mathrm{ng} /$ $\mathrm{ml}$ ) in the United Kingdom (26). This might be due to the prevalent and intense SHS exposure outside home in Hong Kong, where smoking is banned in most indoor public areas but common in the streets with very narrow pavements. Small housing units with windows and doors that are close to each other may facilitate SHS diffusion from neighbors as we found in the previous study (28).
We found that $31.3 \%$ infants were exposed to father's smoking in $3 \mathrm{~m}$ distance, which was higher than the previous local study (21.3\%) in infants in 1997 (25), and also the studies in the United States (27.5\%) (29) and Japan (14.4\%) (30). Smoking near children $(<3 \mathrm{~m})$ was associated with higher odds of hospitalization and significant economic burden $(25,31)$. Our findings suggested that there would be an increase in disease burden for SHS exposure in infants. In this study, the $6.3 \%$ infants who were exposed to smoking within $1.5 \mathrm{~m}$ had significantly increased cotinine levels. Even for fathers who smoked at a distance of $3 \mathrm{~m}$ away, infant's cotinine levels were still significantly higher than those without SHS exposure at home. Smoking near children is abhorred, but smoking $3 \mathrm{~m}$ away from children at home is 


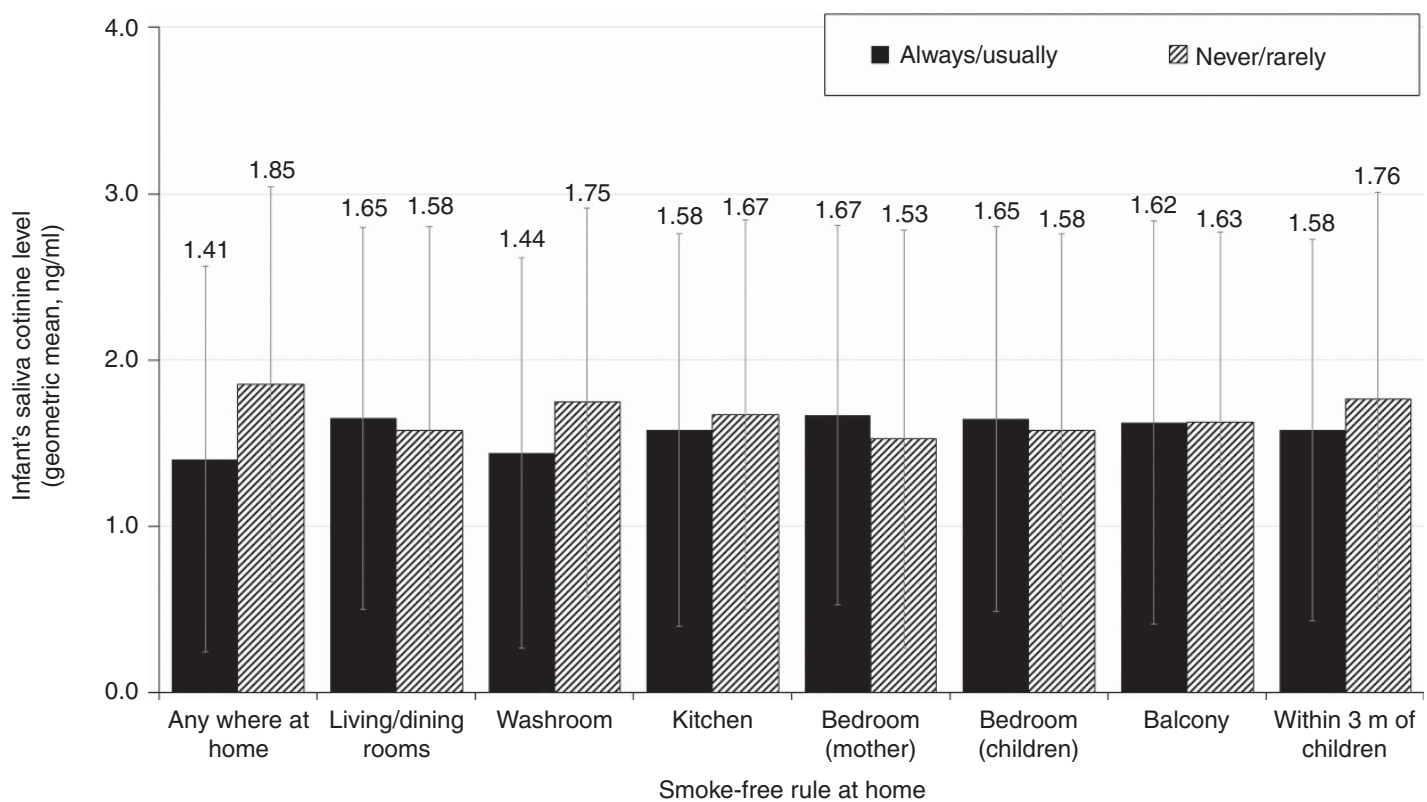

Figure 3. Smoke-free rules at home and infant's saliva cotinine level.

Table 2. Associations of family smoking status and SHS exposure at home, father smoking behaviors, and maternal SHS avoidance actions and smoke-free home rules with infant's cotinine levels

\begin{tabular}{|c|c|c|c|c|}
\hline & \multicolumn{4}{|c|}{$\log _{10}$-transformed saliva cotinine level $(\mathrm{ng} / \mathrm{ml})$} \\
\hline & \multicolumn{4}{|c|}{$\beta$-coefficient (95\% Cl) } \\
\hline & Crude & Model $1^{\mathrm{a}}$ & Model $2^{\mathrm{b}}$ & Model $3^{\mathrm{C}}$ \\
\hline \multicolumn{5}{|l|}{ Among all families which provided saliva $(\mathrm{n}=389)$} \\
\hline \multicolumn{5}{|l|}{ Family smoking status and SHS exposure at home } \\
\hline Non-smoking families & Ref. & Ref. & - & - \\
\hline Smoking families without SHS & $-0.03(-0.12,0.07)$ & $-0.02(-0.09,0.12)$ & - & - \\
\hline Smoking families with SHS & $0.24(0.15,0.32)^{* * * *}$ & $0.25(0.16,0.33)^{* * * *}$ & - & - \\
\hline \multicolumn{5}{|l|}{ Distance that fathers smoked around the children } \\
\hline$>3$ & $0.16(0.06,0.25)^{* *}$ & $0.09(0.01,0.16)^{*}$ & - & - \\
\hline $3-1.51$ & $0.30(0.16,0.44)^{* * * *}$ & $0.30(0.15,0.45)^{* * *}$ & - & - \\
\hline$\leq 1.5$ & $0.82(0.55,1.08)^{* * * *}$ & $0.68(0.42,0.94)^{* * * *}$ & - & - \\
\hline \multicolumn{5}{|l|}{ Among smoking families with SHS $(\mathrm{n}=90)$} \\
\hline \multicolumn{5}{|l|}{ Paternal smoking behaviors } \\
\hline Number of places where fathers smoked (0-6) & $0.16(0.03,0.30)^{*}$ & $0.15(0.18,0.29)^{*}$ & $0.11(-0.03,0.24)$ & $0.11(-0.03,0.25)$ \\
\hline \multicolumn{5}{|l|}{ Distance that fathers smoked around the children } \\
\hline$>3 \mathrm{~m}$ & Ref. & Ref. & Ref. & Ref. \\
\hline $3-1.51 \mathrm{~m}$ & $0.14(-0.08,0.36)$ & $0.21(-0.001,0.42)$ & $0.17(-0.05,0.39)$ & $0.15(-0.07,0.37)$ \\
\hline$\leq 1.5 \mathrm{~m}$ & $0.66(0.28,1.04)^{* * * *}$ & $0.67(0.30,1.04)^{* * * *}$ & $0.62(0.26,0.99)^{* * * *}$ & $0.60(0.22,0.98)^{* *}$ \\
\hline \multicolumn{5}{|l|}{ Maternal protective behaviors } \\
\hline Number of smoke-free rules at home (0-8) & $-0.02(-0.06,0.02)$ & $-0.01(-0.05,0.02)$ & $-0.02(-0.06,0.02)$ & $-0.001(-0.04,0.04)$ \\
\hline Number of maternal SHS avoidance actions (0-6) & $0.07(-0.05,0.18)$ & $0.06(-0.05,0.17)$ & $0.08(-0.03,0.20)$ & $0.04(-0.08,0.15)$ \\
\hline
\end{tabular}

$\mathrm{Cl}$, confidence interval; SHS, second-hand smoke.

${ }^{* * *} P$ value $<0.001,{ }^{* *} P$ value $<0.01$, and ${ }^{*} P$ value $<0.05$

aModel 1: Adjusting for infant's age, household income, parental highest education attainment, type of housing, and outdoor SHS exposure.

${ }^{b}$ Model 2: All adjusted for Model 1 variables; for paternal smoking behaviors mutually adjusted for the number of smoking places and distance; and for mother protective behaviors mutually adjusted for numbers of smoke-free home rules and avoidance actions.

'Model 3: Adjusting for Model 1 variables and mutually adjusted for all variables in the table. 
difficult in practice in Hong Kong due to the typical small living flats. Smokers try to avoid exposing children to SHS by smoking in the kitchen, bathroom, or balcony. However, we found that smoking in these areas was not associated with reduction in infant's cotinine levels. In this regards, none has similar detailed data on places of smoking at home like our study. Western studies found the association between smoking outside the home with doors closed and reduced SHS exposure in infants ( $\leq 1$ year) (32). However, smoking outside the home in the corridors, especially in publicly subsidized housing estates, is mostly prohibited in Hong Kong.

A previous study suggested the important role of engagement in avoidance actions and endorsement of smoke-free home policies by non-smoking mothers in protecting children from SHS exposure (33), especially those in the smoking family. However, we found relatively independent relationship between mother's specific and the number of SHS protection actions, smoke-free home rules, and reduced cotinine level in infants after adjusting for father's smoking behaviors. The findings further support that partial smoking restriction at home was ineffective in reducing SHS in children (34). Recent studies have suggested that third-hand smoke residues that linger on surfaces and in dust after smoking may increase cotinine level in non-smokers (4). It is uncertain if the ineffective maternal SHS protective actions are specific in Chinese society, where families are generally male dominated with strong Confucianist values, and maternal challenges to paternal smoking behaviors may not be effective. Moreover, smoking avoidance behaviors and SHS protective actions are less feasible in small and crowded living units in Hong Kong and many other cities in Mainland China, Asia, and elsewhere.

This study used both self-reported and objective biochemical measurements of SHS exposure (e.g., salivary cotinine). We recruited mother-infant dyads from Maternal and Child Health Centers as over $95 \%$ of young children were registered for their health-care services, mainly for immunization, in Hong Kong (35). However, we only conducted our recruitment in 4 of the 32 centers due to the limitation of resources, which might reduce the representativeness of the sample. The cross-sectional data required caution in inferring causal relationships. The self-reported questionnaire that relied on mother's memory recall is subject to recall bias. For example, mothers may not be able to accurately assess the distance between smoking fathers and children. About half of the respondents refused to provide a saliva sample for cotinine test, due to plausible reasons. Nevertheless, we did not find significant differences in the demographic characteristics and family smoking status between those who provided and those who did not. Cotinine levels in older children higher than $12 \mathrm{ng} / \mathrm{ml}$ were regarded as a possible smoker (36) and were commonly excluded from analysis for SHS exposure. However, as our target group was infants aged 0-18 months, we did not exclude those with high saliva cotinine data given that no procedural and validity errors were identified. The cotinine level could be partially attributed to the third-hand smoke exposure, which was not assessed in this study but deserves further investigation in future.

\section{CONCLUSIONS}

Infant cotinine level was significantly higher in smoking families with SHS exposure. Paternal smoking avoidance behaviors, maternal SHS protective actions, and smoke-free home rules were not effective in reducing infant cotinine. To protect children from SHS, the home should be completely smoke free, and smokers should quit.

\section{SUPPLEMENTARY MATERIAL}

Supplementary material is linked to the online version of the paper at http://www.nature.com/pr

\section{ACKNOWLEDGMENTS}

We are grateful to the participants and the staff of the Maternal and Child Health Centers of the Department of Health. We also thank the research assistants of Smoking Cessation team of School of Nursing, the University of Hong Kong, for project coordination.

\section{STATEMENT OF FINANCIAL SUPPORT}

This study was funded by the Small Project Funding from the University of Hong Kong (no. 201007176256).

Disclosure: The authors declare no conflict of interest.

\section{REFERENCES}

1. Wang MP, Ho SY, Lam TH. Parental smoking, exposure to secondhand smoke at home, and smoking initiation among young children. Nicotine Tob Res 2011;13:827-32.

2. Lam TH, Leung GM, Ho LM. The effects of environmental tobacco smoke on health services utilization in the first eighteen months of life. Pediatrics 2001;107:e91.

3. Lund KE, Skrondal A, Vertio H, Helgason AR. To what extent do parents strive to protect their children from environmental tobacco smoke in the Nordic countries? A population-based study. Tob Control 1998;7:56-60.

4. Matt GE, Quintana PJ, Destaillats H, et al. Thirdhand tobacco smoke: emerging evidence and arguments for a multidisciplinary research agenda. Environ Health Perspect 2011;119:1218-26.

5. Blackburn C, Spencer N, Bonas S, Coe C, Dolan A, Moy R. Effect of strategies to reduce exposure of infants to environmental tobacco smoke in the home: cross sectional survey. BMJ 2003;327:257.

6. Borland R, Yong HH, Cummings KM, Hyland A, Anderson S, Fong GT. Determinants and consequences of smoke-free homes: findings from the International Tobacco Control (ITC) Four Country Survey. Tob Control 2006;15 (Suppl 3): iii42-50.

7. Pizacani BA, Martin DP, Stark MJ, Koepsell TD, Thompson B, Diehr P. A prospective study of household smoking bans and subsequent cessation related behaviour: the role of stage of change. Tob Control 2004;13:23-8.

8. Jarvis MJ, Mindell J, Gilmore A, Feyerabend C, West R. Smoke-free homes in England: prevalence, trends and validation by cotinine in children. Tob Control 2009;18:491-5.

9. Zhang X, Martinez-Donate A, Rhoads N. Parental practices and attitudes related to smoke-free rules in homes, cars, and outdoor playgrounds in US households with underage children and smokers, 2010-2011. Prev Chronic Dis 2015;12:E96.

10. Rosen LJ, Myers V, Hovell M, Zucker D, Ben Noach M. Meta-analysis of parental protection of children from tobacco smoke exposure. Pediatrics 2014;133:698-714.

11. Orton S, Jones LL, Cooper S, Lewis S, Coleman T. Predictors of children's secondhand smoke exposure at home: a systematic review and narrative synthesis of the evidence. PLoS ONE 2014;9:e112690. 


\section{Articles | wang et al.}

12. Johansson A, Hermansson G, Ludvigsson J. How should parents protect their children from environmental tobacco-smoke exposure in the home? Pediatrics 2004;113:e291-5.

13. Mak YW, Loke AY, Abdullah AS, Lam TH. Household smoking practices of parents with young children, and predictors of poor household smoking practices. Public Health 2008;122:1199-209.

14. Chan SS, Cheung YT, Leung DY, Mak YW, Leung GM, Lam TH. Secondhand smoke exposure and maternal action to protect children from secondhand smoke: pre- and post-smokefree legislation in Hong Kong. PLoS ONE 2014;9:e105781.

15. Mills AL, Messer K, Gilpin EA, Pierce JP. The effect of smoke-free homes on adult smoking behavior: a review. Nicotine Tob Res 2009;11:1131-41.

16. Wilson KM, Klein JD, Blumkin AK, Gottlieb M, Winickoff JP. Tobaccosmoke exposure in children who live in multiunit housing. Pediatrics 2011;127:85-92.

17. Ho SY, Wang MP, Lo WS, et al. Comprehensive smoke-free legislation and displacement of smoking into the homes of young children in Hong Kong. Tobacco Control 2010;19:129-33.

18. Willers S, Axmon A, Feyerabend C, Nielsen J, Skarping G, Skerfving S. Assessment of environmental tobacco smoke exposure in children with asthmatic symptoms by questionnaire and cotinine concentrations in plasma, saliva, and urine. J Clin Epidemiol 2000;53:715-21.

19. Jacobsen PB, Manne SL, Gorfinkle K, Schorr O, Rapkin B, Redd WH. Analysis of child and parent behavior during painful medical procedures. Health Psychol 1990;9:559-76.

20. Matt GE, Wahlgren DR, Hovell MF, et al. Measuring environmental tobacco smoke exposure in infants and young children through urine cotinine and memory-based parental reports: empirical findings and discussion. Tob Control 1999;8:282-9.

21. Lee EJ, Arbuckle TE. Urine-sampling methods for environmental chemicals in infants and young children. J Expo Sci Environ Epidemiol 2009;19:625-33.

22. Salimetrics. High Sensitivity salivary cotinine quantitative enzyme immunoassay kit. [Cited 2017 Oct 1], Available from https://www. salimetrics.com/assets/documents/1-2112n.pdf.

23. Anuntaseree W, Mo-Suwan L, Ma ALA, Choprapawon C. Prevalence and associated factors of passive smoking in Thai infants. Prev Med 2008;47:443-6.

24. Baheiraei A, Kharaghani R, Mohsenifar A, et al. Factors associated with secondhand smoke exposure in infants. Tanaffos 2010;9:43-9.
25. Leung GM, Ho LM, Lam TH. Secondhand smoke exposure, smoking hygiene, and hospitalization in the first 18 months of life. Arch Pediatr Adolesc Med 2004;158:687-93.

26. Akhtar PC, Currie DB, Zachary R, Currie CE. Smoking restrictions in the home and secondhand smoke exposure among primary schoolchildren before and after introduction of the Scottish smokefree legislation. Tob Control 2009;18:409-15.

27. Brunst KJ, Ryan PH, Lockey JE, et al. Unraveling the relationship between aeroallergen sensitization, gender, second-hand smoke exposure, and impaired lung function. Pediatr Allergy Immunol 2012;23:479-87.

28. Leung LT, Ho SY, Wang MP, Lo WS, Lam TH. Exposure to secondhand smoke from neighbours and respiratory symptoms in never-smoking adolescents in Hong Kong: a cross-sectional study. BMJ Open 2015;5: e008607.

29. Joseph A, Murphy S, Thomas J, et al. A pilot study of concurrent lead and cotinine screening for childhood tobacco smoke exposure: effect on parental smoking. Am J Health Promot 2014;28:316-20.

30. Saito J, Tabuchi T, Shibanuma A, Yasuoka J, Nakamura M, Jimba M. 'Only Fathers Smoking' contributes the most to socioeconomic inequalities: changes in socioeconomic inequalities in infants' exposure to second hand smoke over time in Japan. PLoS ONE 2015;10: e0139512.

31. Leung GM, Ho LM, Lam TH. The economic burden of environmental tobacco smoke in the first year of life. Arch Dis Child 2003;88: 767-71.

32. Matt GE, Quintana PJ, Hovell MF, et al. Households contaminated by environmental tobacco smoke: sources of infant exposures. Tob Control 2004;13:29-37.

33. Blackburn CM, Bonas S, Spencer NJ, Coe CJ, Dolan A, Moy R. Parental smoking and passive smoking in infants: fathers matter too. Health Educ Res 2005;20:185-94.

34. Baxi R, Sharma M, Roseby R, et al. Family and carer smoking control programmes for reducing children's exposure to environmental tobacco smoke. Cochrane Database Syst Rev 2014;1:CD001746.

35. Department of Health. Family Health Services Maternal and Child Health Centres. Hong Kong SAR, China: Department of Health 2006.

36. Jarvis MJ, Fidler J, Mindell J, Feyerabend C, West R. Assessing smoking status in children, adolescents and adults: cotinine cut-points revisited. Addiction 2008;103:1553-61. 